\title{
Risk Factors of Overweight among Urban School-Going Adolescents: A Case-Control Study
}

\author{
Bibechana Sapkota, ${ }^{1}$ Tulsi Ram Bhandari ${ }^{1}$ \\ ${ }^{1}$ School of Health and Allied Sciences, Faculty of Health Sciences, Pokhara University, Nepal
}

\begin{abstract}
Introduction: Obesity is seen high in rapid economic growth, industrialized and urbanized area. CBS 2012 report showed that Nepal is urbanizing at a fast pace which show that Nepal is also at the risk of obesity problem. The study aim was to study the risk factors associated with overweight among urban school-going adolescents.

Methods: In this institution based case-control study, age, sex and ethnicity matched 63 cases (BMI $\geq 25)$ and 63 controls (BMI 18.5- 24.99) adolescents between 13-16 years were recruited. Self administer question was used to collect data from case and control. Data were entered in Epi Data 3.1 and analysis was done using SPSS 20.0 full version. Crude odd ratio was calculated to assess the risk factors associated with overweight.

Results: Regular meat consumption $(\mathrm{OR}=3.47)$, consumption of fruit $<3$ days per week $(\mathrm{OR}=2)$, regular consumption of junk food $(\mathrm{OR}=2.564) \geq 5 \mathrm{DDS}(\mathrm{OR}=2.591)$ significantly increase the risk of overweight. Cases were 6.259 times more likely to do dieting for physical fitness as compare to control similarly irregular menstruation was 4.960 times noted among controls.

Conclusion: Regular consumption of meat, junk food and soft drink, likewise family history with obesity, the habit of dieting for weight-loss purposes, irregular menstruation and screen viewing lead to obesity among adolescent in Lekthnath city in Pokhara metropolitan.
\end{abstract}

Keywords: overweight, obesity, adolescents, risk factors, Nepal

\section{INTRODUCTION}

The adolescent is the period of physical, psychological and social maturing from childhood to adulthood. The term adolescent refers to individuals between the ages of 10-19 years. ${ }^{1}$

Anthropometry is the best and important indicator use to assess the nutritional status of human. Among the various anthropometric indicator uses to assess the nutritional status Body Mass Index (BMI) is the one. ${ }^{2}$ Weight for height and BMI could be the appropriate indicator used in the assessment of nutritional status among adolescent. ${ }^{3}$

Worldwide the prevalence of obesity has risen from just four percent in 1975 to just over $18 \%$ in 2016 among children aged 5-19 years i.e obesity problem increase by ten fold in four decades. ${ }^{4}$ The rise in overweight and obesity even in low and middle-income countries like Nepal may be due to ongoing urbanization and economic transitions. ${ }^{5}$ Childhood obesity is particularly prevalent in rapid economic growth, industrialized and, urbanized area. ${ }^{6}$ Economic transition and the urbanization increase the levels of lifestyle-related risk factors such as low physical activity and unhealthy dietary habits. ${ }^{7}$

The prevalence of overweight and obesity have previously been higher in developed countries but in recent years the prevalence in many low and middle-income countries has reached the levels in developed nations. ${ }^{8,9}$ The systematic review of 11 studies conducted in India, Pakistan and Bangladesh shows that nutrition transition contribute to overweight problem among adolescents in South Asian countries. ${ }^{10}$ Most of the children preferred unhealthier food-items and low physical activities which are the risk factor for overweight and obesity ${ }^{11}$ which contribute to the non-communicable diseases as overweight and obesity are the major risk factors for NCD. ${ }^{12,13}$ In Nepal $66 \%$ of all deaths account from NCD of which $30 \%$ of death are from cardiovascular diseases. ${ }^{14}$ In Nepal, adolescents comprise (23.45\%) of the total population. ${ }^{15}$ A WHO step survey conducted in Nepal among Nepalese people (15-69 years age) reported the prevalence of overweight and obesity to be $21.7 \%{ }^{16}$ Nepal urban population increased from $13.9 \%$ in 2001 to $17 \%$ in 2011 of the total population which show that it is urbanizing at fast pace and is also at the risk of obesity problem. ${ }^{17}$

Lekthnath city of Pokhara metropolitan is an urban community and overweight among adolescents is on increasing trend with

Correspondence: Bibechana Sapkota Pandey, Masters in Public Health Pokhara Univeristy, Pokhara, Nepal, E-mail: bibechanasapkota@ gmail.com 
the pace of urbanization and development. The increasing population, location, urbanization, diversity, and influence of city life all make lekthnath city of Pokhara metropolitan an area to study about obesity. Till date very few research studies have been conducted on overweight among adolescents in Nepal. Though the study is done only cross-sectional study is done not a single case-control study regarding adolescent overweight is carried out in Nepal. Therefore, the aim of this study was to study risk factors of overweight among adolescents, and the information may be useful for predicting the situation in similar settings and baseline for future research.

\section{METHODS}

This Study was conducted in 14 private school of Pokhara metropolitan ward no 29, 30 and 32 which lies in Lekthnath city. Study was confined only in private schools because student studying in private school are twice as likely to be overweight than those studying in public school. ${ }^{18}$ This was a case-control study with 63 cases and 63 controls among private school-going adolescents aged 13-16 years and studying in grade nine and ten to establish causal association of overweight with its risk factors. The cases (after refered overweight) and controls (after refered normal weight) were recruited from 14 different private school of lekthnath city and segregated according to WHO body mass index (BMI) cut off value. ${ }^{2}$ BMI $\geq 25$ and between 18.5 to 24.9 were considered as cases and controls respectively. Age, sex and ethnicity matched cases and controls were recruited on a $1: 1$ ratio individually from the same school.

Sample size was calculated using the software Open Epi. Considering $80 \%$ power, $95 \%$ confidence level, case-control ratio 1:1 and using Felsi with CC sample for case and control was 126 (case 63 and control 63) to detect at least 3.10 odd ratio differences between cases and controls. Ethical approval letter was obtained from Institutional Review Committee of Pokhara University. Approval was taken from Ministry of education, science and technology (education division) which was the previous District education office, Kaski and from the private secondary schools for the study. Written consent was taken from participants as well as their parents as the participants were below 18 years.

Body weight and height were measured within the school premises using digital weighing scale and plastic portable stadiometer. The accuracy of the instrument was checked using standar weight and height at the beginning in each session and after measuring of every five students. Similarly anthropometric measurement toll was validated from Nepal Bureau of Standard and Metrology (NBSM), Pokhara branch.
Self-administered questionnaire was used to collect the information from the participant. Questionnaire was divided into three sections. First section consists of dietary information which includes food habit and dietary diversity (DD) question. For dietary diversity individual dietary diversity questionnaire developed by FAO/Nutrition and consumer protection division used in adolescent nutrition survey in 2014 was adopted similarly food habit question was also adopted from adolescent nutrition survey in 2014. ${ }^{19,20}$ Individual dietary diversity was categorized based on the mean score obtained by the participant as $\geq 5$ DDS (Dietary Diversity Score) and $<5$ DDS as 5 mean Dietary Diversity Score was obtained. Second section consists of Information regarding physical activity and screen viewing time, regarding physical activity Global physical activity questionnaire (GPAQ) developed by World health organization (WHO) which was used in the WHO step survey was adopted . ${ }^{21}$

Another screen viewing question was developed by researcher herself. Physical activity was categorized into less physically active ( $<3000 \mathrm{MET}$-min/week), and highly active ( $\geq 3000 \mathrm{MET}$ $\mathrm{min} /$ week), based on the total MET (metabolic equivalent) time spend in different activity like work -related activity, recreational activity and time spend for walking by the participants. Third section consists of Information regarding personal factors (step taken for physical fitness and menstruation regularity) and family history (family member with obesity) developed by the researcher herself through intensive literature review and consultation with the supervisor.

Pretesting of the final version of questionnaires was done in the similar setting of the nearby district among $10 \%$ of total sample size adolescent then feedbacks from the pretesting was incorporated into the final version of the questionnaire to ensure the validity of the study tools regarding its contents and information. The crude Odds ratio (OR) and its $95 \%$ confidence interval (CI) were also estimated and computed. Cross tab was done for each variable of interest with outcome variable separately for the association and to calculate OR using SPSS 22.0 versions.

\section{RESULTS}

A school based case control study was conducted to assess the risk factors associated with overweight among urban school-going adolescents of Pokhara metropolitan. The study population consisted of 126 adolescents aged between 13-16 years with 63 cases and 63 controls. Demographic characteristics of the respondent were describe and Cross tab was done for each variable of interest with outcome variable separately for the association and to calculate OR using SPSS 22.0 versions. 
Table 1: Demographic characteristics of the respondent

\begin{tabular}{lcc}
\hline Characteristics & Frequency $(\mathrm{n}=126)$ & Percent \\
\hline Age & & \\
13-14 years & 14 & 11.1 \\
15-16 years & 112 & 88.9 \\
Sex & & \\
Male & 54 & 42.9 \\
Female & 72 & 57.1 \\
Ethnicity & & \\
Dalit & 12 & 9.5 \\
Janajati & 84 & 66.7 \\
Brahmin/chhetri & 30 & 23.8 \\
\hline
\end{tabular}

In this study majority of the respondent were with in the age group of 15-16 and over half of the respondents were female and belong to janajati ethnic group (table 1).

Table 2: Association between overweight and their food habit

\begin{tabular}{|c|c|c|c|c|}
\hline Characteristics & $\begin{array}{l}\text { Case } \\
\mathrm{n}(\%) \\
\end{array}$ & $\begin{array}{l}\text { Control } \\
\mathrm{n}(\%)\end{array}$ & OR & $\begin{array}{l}95 \% \\
\mathrm{CI} \\
\end{array}$ \\
\hline \multicolumn{5}{|l|}{ Non-vegetarian } \\
\hline Yes & $58(48.7)$ & $61(51.3)$ & .380 & $\begin{array}{l}(.071- \\
2.03)\end{array}$ \\
\hline No & $5(71.4)$ & $2(28.6)$ & 1 & \\
\hline \multicolumn{5}{|l|}{ Frequency of eating meat } \\
\hline Regular ( $\geq 3$ days/week) & $14(73.7)$ & $5(26.3)$ & 3.470 & $\begin{array}{l}(1.16- \\
10.34)\end{array}$ \\
\hline Irregular ( $<3$ days/week) & $46(44.7)$ & $57(55.3)$ & 1 & \\
\hline \multicolumn{5}{|l|}{ Frequency of eating Vegetable } \\
\hline$<7$ days/week & $26(48.1)$ & $28(51.9)$ & .878 & $\begin{array}{l}(.434- \\
1.78)\end{array}$ \\
\hline 7 days/week & $37(51.4)$ & $35(48.6)$ & 1 & \\
\hline \multicolumn{5}{|l|}{ Frequency of eating fruit } \\
\hline$<3$ days/week & $31(62.0)$ & $19(38.0)$ & 2.243 & $\begin{array}{l}(1.081- \\
4.6)\end{array}$ \\
\hline$\geq 3$ days/week & $32(42.1)$ & $44(57.9)$ & & \\
\hline \multicolumn{5}{|l|}{ Frequency of eating junk food } \\
\hline Regular ( $\geq 3$ days/week) & $50(58.1)$ & $36(41.9)$ & 2.564 & $\begin{array}{l}(1.15- \\
5.70)\end{array}$ \\
\hline Irregular ( $<3$ days/week) & $13(35.1)$ & $24(64.9)$ & & \\
\hline \multicolumn{5}{|l|}{ Frequency of eating fast food } \\
\hline Regular ( $\geq 3$ days/week) & $8(38.1)$ & $13(61.9)$ & .581 & $\begin{array}{l}(.222- \\
1.51)\end{array}$ \\
\hline Irregular ( $<3$ days/week) & $53(51.5)$ & $50(48.5)$ & & \\
\hline \multicolumn{5}{|l|}{ Frequency of taking soft drink } \\
\hline Regular ( $\geq 3$ days/week) & $20(71.4)$ & $8(28.6)$ & 2.907 & $\begin{array}{l}(1.16- \\
7.26)\end{array}$ \\
\hline Irregular ( $<3$ days/week) & $43(46.2)$ & $50(53.8)$ & 1 & \\
\hline \multicolumn{5}{|l|}{ Food intake in a day } \\
\hline $4-5$ times & $22(45.8)$ & $\begin{array}{l}26 \\
(54.20)\end{array}$ & .764 & $\begin{array}{l}(.371- \\
1.57)\end{array}$ \\
\hline$\leq 3$ times & $41(52.6)$ & $37(47.4)$ & 1 & \\
\hline
\end{tabular}

The risk of becoming overweight was 3.47 times more in regular meat-eaters than irregular meat-eaters $(95 \% \mathrm{CI}=1.164-10.345)$. The risk of becoming overweight was 2.243 times more among the respondents who consumed fruits less than 3 days in a week (95\% CI $=1.081-4.657)$. Odds of overweight was 2.564 times more among the respondents who ate junk food regularly $(95 \%$ $\mathrm{CI}=1.153-5.703)$. On applying odds ratio it was found that risk of overweight was 2.907 times more among the respondents who took soft drinks regularly $(95 \% \mathrm{CI}=1.164-7.263)$ in comparison with irregular consumer (table 2).

Table 2: Association between overweight and their Dietary Diversity Score

\begin{tabular}{lcccc}
\hline Characteristics & $\begin{array}{c}\text { Case } \\
\mathrm{n}(\%)\end{array}$ & $\begin{array}{c}\text { Control } \\
\mathrm{n}(\%)\end{array}$ & OR & $95 \% \mathrm{CI}$ \\
\hline \multicolumn{4}{l}{ Dietary Diversity } & Score \\
$\geq 5$ DDS & $54(55.1)$ & $44(44.9)$ & 2.591 & $1.067-6.293$ \\
$\quad$ <DDS & $9(32.1)$ & $19(67.9)$ & & \\
\hline
\end{tabular}

The association between overweight and their Dietary diversity score showed that cases were 2.591 times more likely to had greater than 5 Dietary diversity score (95\% CI= 1067-6.293).

Table 3: Association between overweight and their physical activity and screen viewing time

\begin{tabular}{lclll}
\hline Characteristics & Casen $(\%)$ & Controln(\%) & OR & $95 \%$ CI \\
\hline $\begin{array}{l}l \\
\text { Level of Physical activity }\end{array}$ & & & \\
Less physically active & $55(54.5)$ & $46(45.5)$ & 2.54 & $1.56-7.34$ \\
Highly physically active & $8(32.0)$ & $17(68.0)$ & & \\
Screen viewing time & & & & \\
$\geq 2$ Hours & $49(60.50)$ & $32(39.50)$ & 3.39 & $1.0-6.42$ \\
$<2$ Hours & $14(31.10)$ & $31(68.90)$ & & \\
\hline
\end{tabular}

Cases were 2.54 times more likely to be less physically active as compared to control similarly case were 3.39 times more likely to have higher screen viewing time compared to control (table 26).

Table 27: Association between overweight and their personal factors and family history

\begin{tabular}{|c|c|c|c|c|}
\hline \multirow{2}{*}{ Characteristics } & Case & Control & \multirow{2}{*}{$\begin{array}{l}\text { OR } \\
(95 \% \mathrm{CI})\end{array}$} & \multirow{2}{*}{$95 \% \mathrm{CI}$} \\
\hline & $\mathrm{n}(\%)$ & $\mathrm{n}(\%)$ & & \\
\hline \multicolumn{5}{|c|}{ Step taken for physical fitness } \\
\hline Yes & $32(60.4)$ & $21(39.6)$ & 2.065 & $1.005-4.241$ \\
\hline No & $31(42.5)$ & $42(57.5)$ & 1 & \\
\hline \multicolumn{5}{|l|}{ Dieting } \\
\hline Yes & $26(74.3)$ & $9(25.7)$ & 6.259 & $1.831-21.392$ \\
\hline No & $6(31.6)$ & $13(68.4)$ & 1 & \\
\hline \multicolumn{5}{|c|}{ Family member with obesity } \\
\hline Yes & $55(59.1)$ & $38(40.9)$ & 4.523 & $1.844-11.093$ \\
\hline No & $8(24.2)$ & $25(75.8)$ & 1 & \\
\hline \multicolumn{5}{|l|}{ Menstruation } \\
\hline Irregular & $16(44.4)$ & $5(13.9)$ & 4.960 & $1.569-15.677$ \\
\hline Regular & $20(55.6)$ & $31(86.1)$ & 1 & \\
\hline
\end{tabular}


Cases were 2.065 (95\% CI 1.005-4.241) and 6.259 (95\% CI 1.831-21.392) times more likely to take the step for physical fitness and do dieting for fitness respectively. Respondents having family members with obesity were 4.523 times more likely to be overweight ( $95 \% \mathrm{CI}=1.844-11.093)$. Similarly, irregular menstruation was 4.960 times more likely among cases (table 27).

\section{DISCUSSION}

Our data suggest that risk of becoming overweight was significantly higher among adolescents who were vegetarians similarly regular consumption of meat, junk food and soft drink, likewise family history of obesity, the habit of dieting for weightloss purposes, irregular menstruation and screen viewing time were identified as risk factors for obesity during adolescence. The habit of having food for more than four times daily seems to be a protective factor against overweight.

Odds of consuming meat regularly were 3.470 times higher in cases as compare to control which is inconsistent with the studies conducted in Hawassa city of Southern Ethiopia and Sao Paulo city of southern eastern Brazil where no association was seen with meat consumption frequency. ${ }^{22,23}$ Likewise odds of consuming fruit irregularly were 2.243 times higher in cases than controls which is supported by the findings of study conducted in Wayamba city of Sri Lanka (AOR 2.18; 95\% CI:1.02-4.67), Hawassa city of Southern Ethiopia (AOR=2.16, 95\% CI: 1.08 4.33), Kalutara district of Sri Lanka and Center-West Region of Brazil. ${ }^{22,24-26}$ Which is inconsistent with the study conducted in Pelotas city of Brazil where no association was seen with fruit consumption frequency. ${ }^{27}$ It might be because of different in dietary pattern in different countries.

Odds of consuming junk food regularly were 2.564 times higher in cases than controls which is supported by the findings of study conducted in Hyderabad city of India ${ }^{28}$ which is inconsistent with the study conducted in Sao Paulo city of southern eastern Brazil where no association was seen. ${ }^{23}$ Similarly odds of consuming soft drink regularly were 2.907 times higher in cases than controls which is consistent with the studies conducted in Navarra city of Spain, Kalutara district of Srilanka ${ }^{25,29}$ which is inconsistent with the studies conducted in Sao Paulo city of southern eastern Brazil, Hawassa city of Southern Ethiopia and Pelotas city of Brazil where no association is seen. ${ }^{22,23,27}$ It might be because of different in dietary pattern in different countries. Cases were 2.53 (95\% CI: 1.356-4.727) times more likely to be physically inactive than control which is consistent with the study conducted in Sweden, Kalutara district of Srilanka (AOR 1.6, 95\% CI 1.1-2.4), Wayamba city of Sri Lanka, and Hyderabad city of India. ${ }^{24,25,30}$ Which is inconsistent with the study conducted in Sao Paulo city of southern eastern Brazil, Center-West Region of Brazil, Navarra city of Spain ,Bangladesh, Hawassa city of Southern Ethiopia, Pelotas city of Brazil where no association was seen with physical activity. ${ }^{22,23,26,27,29,31}$ It might be because in this study GPAQ which seems appropriate for an adult was used. Cases were 2.53 (95\% CI: 1.356-4.727) times more likely to spent $>3 \mathrm{~h}$ per day of screen time (TV ,mobile computer and others) than control which is consistent with the study conducted in Bangladesh $(\mathrm{AOR}=2.0,95 \% \mathrm{CI}: 1.1-3.7)$, Center-West Region of Brazil, Kalutara district Srilanka, Wayamba city of Sri Lanka, Pelotas city of Brazil, and Hyderabad city of India where significant association is seen ${ }^{24-27,31}$ It is inconsistent with the study conducted in Sao Paulo city of southern eastern Brazil, and Navarra city of Spain where no association is seen with screen viewing time. ${ }^{23,29}$

Case reported 4.523 times higher chance to have obese family member as compare to control which is consistent with the study conducted in Sao Paulo city of southern eastern Brazil (AOR 2.23; 95\%CI: 1.15-4.35), Center-West Region of Brazil, Bangladesh $(\mathrm{AOR}=2.8 ;$ 95\%CI: 1.5-5.2), and Pelotas city of Brazil..23, 26, 27,31 Overweight adolescents were 6.259 times more likely to do dieting for physical fitness and weight loss as compared to the normal weight which is consistent with the study conducted in Sao Paulo city of southern eastern Brazil (AOR 7.26; 95\% CI 2.95-17.88), Center-West Region of Brazil and Pelotas city of Brazil. 23, 26, 27 Irregular menstruation was 4.96 times more likely to be seen among cases as compared to controls which is supported by the finding of the study conducted in Wayamba city of Sri Lanka. ${ }^{24}$

\section{LIMITATIONS}

Respondents could fail to provide correct responses to some of the questions and might introduce recall bias to the data. As it is school-based, and confined only in private school the study had not included adolescents out of private schools which might have result significant difference in some variable and it lacks a qualitative method. As this study was confined only in Lekthnath city it cannot be generalized.

\section{CONCLUSION}

The current study demonstrated several risk factors such as regular consumption of meat, junk food and soft drink, likewise family history with obesity, the habit of dieting for weight-loss purposes, irregular menstruation and screen viewing associated with overweight among urban school-going adolescent in Lekthnath city, Pokhara Metropolitan. The habit of having food for more than four times daily seems to be a protective factor against overweight. Adolescents focused obesity control policies and the program should be conducted to increase awareness on risk factors among adolescents. The interventional study is 
suggested giving special attention to female and the adolescents belonging to janajati ethnic group as they were found as risk factors for overweight.

\section{REFERENCES}

1. WHO, UNICEF. The reproductive health of adolescents: a strategy for action. 1989.

2. WHO. Use and interpretation of anthropometric indicators of nutritional status. Bulletin of the World Health Organization. 1986;64(Report).

3. Woodruff B, Duffield A. Anthropometric assessment of nutritional status in adolescent populations in humanitarian emergencies. European journal of clinical nutrition. 2002;56(11):1108.

4. WHO. Fact sheet: Obesity and overweight Geneva: 2018 16 February 2018. Report No.

5. Popkin BM. Global nutrition dynamics: the world is shifting rapidly toward a diet linked with noncommunicable diseases. The American journal of clinical nutrition. 2006;84(2):289-98.

6. Aryal M. Childhood Obesity, Unrecognized public health challenge in Nepal. Kathmandu University Medical Journal. 2010;8(4):358-9.

7. WHO. Preventing and managing the global epidemic of obesity. Report of the World Health Organization Consultation on Obesity Geneva: World Health Organization. 1997.

8. Finucane MM, Stevens GA, Cowan MJ, Danaei G, Lin JK, Paciorek CJ, et al. National, regional, and global trends in body-mass index since 1980: systematic analysis of health examination surveys and epidemiological studies with 960 country-years and 9.1 million participants. The Lancet. 2011;377(9765):557-67.

9. Jones-Smith JC, Gordon-Larsen P, Siddiqi A, Popkin BM. Cross-national comparisons of time trends in overweight inequality by socioeconomic status among women using repeated cross-sectional surveys from 37 developing countries, 1989-2007. American journal of epidemiology. 2011;173(6):667-75.

10. Mistry SK, Puthussery S. Risk factors of overweight and obesity in childhood and adolescence in South Asian countries: a systematic review of the evidence. Public health. 2015;129(3):200-9.

11. Vaidya A, Oli N, Krettek A, Eiben G. Preference of Fooditems and Physical Activity of Peri-urban Children in Bhaktapur. Journal of Nepal Health Research Council. 2017;15(2):150-8.

12. Kohl 3rd HW, Craig CL, Lambert EV, Inoue S, Alkandari JR, Leetongin G, et al. The pandemic of physical inactivity: global action for public health. The lancet. 2012;380(9838):294-305.

13. Mendis S. Global status report on noncommunicable diseases 2014: World health organization; 2014.

14. WHO. Non communicable Diseases (NCD) country profile 2018.

15. Go N. National Population and housing census 2011 (National Report). Edited by Statistics CBo. 2012;1.

16. STEP I. Non communicable diseases risk factors: steps survey Nepal. 2013.

17. CBS. National Population and Housing Census 2011. Kathmandu, Nepal: NPC, CBS, 2012.

18. Piryani S, Baral KP, Pradhan B, Poudyal AK, Piryani RM. Overweight and its associated risk factors among urban school adolescents in Nepal: a cross-sectional study. BMJ open. 2016;6(5):e010335.

19. Kennedy G, Ballard T, Dop MC. Guidelines for measuring household and individual dietary diversity: Food and Agriculture Organization of the United Nations; 2011.

20. Nepal Health Research Council G. Adolescent Nutrition Survey in Nepal. 2014.

21. Mathews E, Salvo D, Sarma PS, Thankappan KR, Pratt M. Peer Reviewed: Adapting and Validating the Global Physical Activity Questionnaire (GPAQ) for Trivandrum, India, 2013. Preventing chronic disease. 2016;13.

22. Bereket AH, Beyero M, Fikadu AR, Bosha T. Risk factors for overweight and obesity in private high school adolescents in Hawassa city, Southern Ethiopia: a casecontrol study. Food Public Health. 2017;7(7):29-34.

23. Silveira D, De Aguiar Carrazedo Taddei JA, Escrivão MAMS, Oliveira FLC, Ancona-Lopez F. Risk factors for overweight among Brazilian adolescents of low-income families: a case-control study. Public health nutrition. 2006;9(4):421-8.

24. Rathnayake KM, Roopasingam T, Wickramasighe VP. Nutritional and behavioral determinants of adolescent obesity: a case-control study in Sri Lanka. BMC public health. 2014;14:1291.

25. Godakanda I, Abeysena C, Lokubalasooriya A. Sedentary behavior during leisure time, physical activity and dietary habits as risk factors of overweight among school children aged 14-15 years: case control study. BMC research notes. 2018;11(1):186.

26. Menezes ICF, Neutzling MB, Taddei JdAC. Risk factors for overweight and obesity in adolescents of a Brazilian University: a case-control study. Nutricion hospitalaria. 2009;24(1):17-24.

27. Neutzling MB, Taddei JAAC, Gigante DP. Risk factors of obesity among Brazilian adolescents: a case-control study. Public health nutrition. 2003;6(8):743-9. 
28. Prasad V, Katta H, Malhotra V. Risk Factors associated with obesity among adolescent students: A case control study. Int J Health Sci Res. 2015;5:1-5.

29. Martin-Calvo N, Martínez-González M-A, Bes-Rastrollo M, Gea A, Ochoa MC, Marti A, et al. Sugar-sweetened carbonated beverage consumption and childhood/ adolescent obesity: a case-control study. Public health nutrition. 2014;17(10):2185-93.

30. Ekelund U, Aman J, Yngve A, Renman C, Westerterp
KR, Sjostrom M, et al. Physical activity but not energy expenditure is reduced in obese adolescents: a casecontrol study. American Journal of Clinical Nutrition. 2002;76(5):935-41.

31. Bhuiyan MU, Zaman S, Ahmed T. Risk factors associated with overweight and obesity among urban school children and adolescents in Bangladesh: a case-control study. BMC pediatrics. 2013;13(1):72-. 